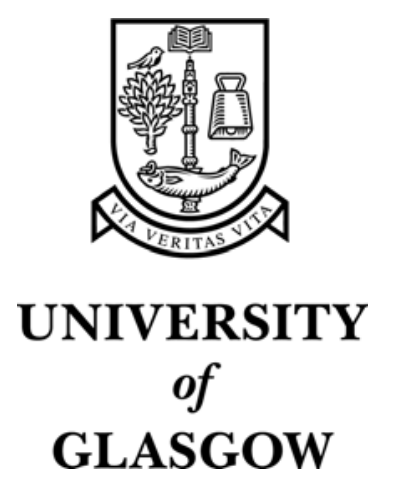

Gallegos-Lopez, G. and Kjaer, P.C. and Miller, T.J.E. (1998) A new sensorless method for switched reluctance motor drives. IEEE Transactions on Industry Applications 34(4):pp. 832-840.

http://eprints.gla.ac.uk/archive/00002838/ 


\section{A New Sensorless Method for Switched Reluctance Motor Drives}

Gabriel Gallegos-López, Student Member, IEEE, Philip C. Kjaer, Member, IEEE, and Timothy J. E. Miller, Fellow, IEEE

\begin{abstract}
This paper describes a new method for indirect sensing of the rotor position in switched reluctance motors (SRM's) using pulsewidth modulation voltage control. The detection method uses the change of the derivative of the phase current to detect the position where a rotor pole and stator pole start to overlap, giving one position update per energy conversion. As no a priori knowledge of motor parameters is required (except for the numbers of stator and rotor poles), the method is applicable to most SRM topologies in a wide power and speed range and for several inverter topologies. The method allows modest closed-loop dynamic performance. To start up the motor, a feedforward stepping method is used which assures robust startup (even under load) from standstill to a predefined speed at which closed-loop sensorless operation can be applied. Experimental results demonstrate the robust functionality of the method with just one current sensor in the inverter, even with excitation overlap, and the sensorless operation improves with speed. The method is comparable to the back-EMF position estimation for brushless dc motors in principle, performance, and cost. A detailed operation and implementation of this scheme is shown, together with steady-state and dynamic transient test results.
\end{abstract}

Index Terms - Adjustable-speed drives, sensorless control, switched reluctance motors.

\section{INTRODUCTION}

$\mathbf{I}$ N RECENT YEARS, the switched reluctance motor (SRM) has received considerable attention for variable-speed drive applications. Its simple construction, due to the absence of magnets, rotor conductors, and brushes, and high system efficiency over a wide speed range make the SRM drive an interesting alternative to compete with permanent magnet (PM) brushless dc motor and induction motor drives. However, the need for a direct rotor position sensor to commutate the current from phase to phase synchronously with rotor position has excluded the motor from many cost-sensitive applications. Fig. 1 shows a 6/4 three-phase SRM.

An encoder, resolver, or Hall sensor attached to the shaft is normally used to supply the rotor position, but the use of these

Paper IPCSD 98-22, presented at the 1997 Industry Applications Society Annual Meeting, New Orleans, LA, October 5-9, and approved for publication in the IEEE TRANSACTIONS ON INDUSTRY APPLICATIONS by the Industrial Drives Committee of the IEEE Industry Applications Society. The work of G. Gallegos-López was supported by Consejo Nacional de Ciencia y Tecnología México (CONACyT). Manuscript released for publication March 11, 1998.

G. Gallegos-López and T. J. E. Miller are with the SPEED Laboratory, Department of Electronics and Electrical Engineering, University of Glasgow, Glasgow G12 8LT, Scotland, U.K.

P. C. Kjaer was with the SPEED Laboratory, Department of Electronics and Electrical Engineering, University of Glasgow, Glasgow G12 8LT, Scotland, U.K. He is now with ABB Corporate Research, 72178 Västerås, Sweden.

Publisher Item Identifier S 0093-9994(98)04908-1.

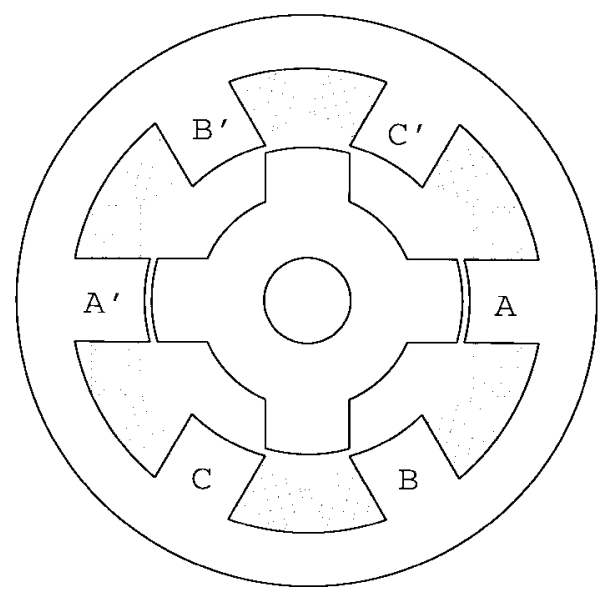

Fig. 1. 6/4 three-phase SRM.

TABLE I

MOTOR RATINGS

\begin{tabular}{l|l}
\hline 3 phases stator/rotor poles & $6 / 4$ \\
\hline Stator pole-arc & $33.12^{\circ}$ \\
\hline Rotor pole-arc & $37.8^{\circ}$ \\
\hline Phase resistance & $4.79 \Omega$ \\
\hline Stator OD & $71.7 \mathrm{~mm}$ \\
\hline Stack length & $50.8 \mathrm{~mm}$ \\
\hline Max. inductance $L_{a}$ not saturated & $118.0 \mathrm{mH}$ \\
\hline Min. inductance $L_{u}$ & $14.66 \mathrm{mH}$ \\
\hline Ratio $L_{a} / L_{u}$ & 8.049 \\
\hline Total motor weight & $1.895 \mathrm{~kg}$ \\
\hline Wire diameter & $0.6 \mathrm{~mm}$ \\
\hline$I_{m a x}$ & $6 \mathrm{~A}$ \\
\hline $1_{r m s}$ & $3.46 \mathrm{~A}$ \\
\hline Rated torque & $0.7 \mathrm{Nm}$ \\
\hline Rated speed & $800 \mathrm{rpm}$ \\
\hline DC-link voltage & $70 \mathrm{~V}$ \\
\hline
\end{tabular}

sensors may lead to reliability problems in harsh environments or may become an important part of the overall drive system cost for drives below 1-hp. Also, they increase the overall physical envelope of the motor drive and the number of extra wires.

In this paper, a new method for indirect sensing of the rotor position in SRM's using PWM voltage control is proposed. The paper is structured as follows: a brief review of indirect methods for position detection is given, followed by a theoretical examination of the proposed current gradient sensorless method (CGSM), the implementation of the method and experimental results, a detailed account of the startup 


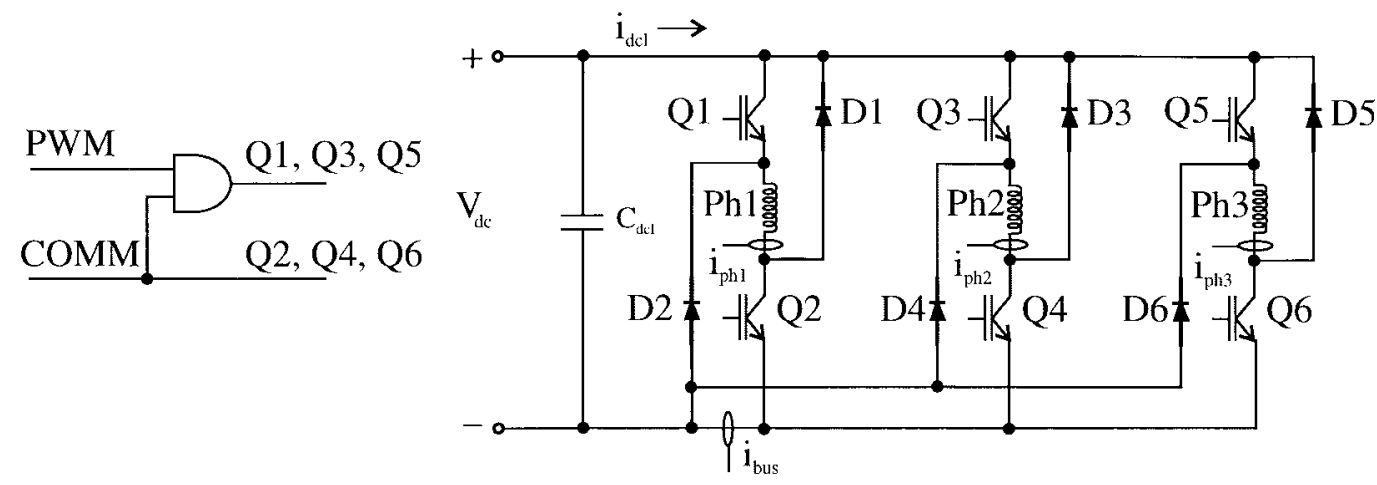

Fig. 2. Classic SRM inverter with lower rails divided showing current sensor placements.

procedure, and conclusions. Table I shows the ratings of the motor used.

\section{A. Review}

All SRM's possess a unique relationship between phase inductance, phase current, and rotor position, which makes prediction of rotor position possible. Several indirect rotor position methods have been proposed in the literature, all making use of the inductance variation in one way or another. For example, the chopping current detection technique by Acarnley et al. [1], the flux-current detection technique by Lyons et al. [2] and Hedlund [3], the impedance sensing by Acarnley et al. [1] and MacMinn et al. [4], the modulation techniques by Ehsani et al. [5], [6], the mutually induced voltage by Husain [7], the resonant method by Laurent et al. [8], and the open-loop control by Bass et al. [9]. A more sophisticated method is the state observer presented by Lumsdaine [10], but it requires a powerful digital signal processor (DSP). Most of the proposed sensorless methods require some knowledge of the motor's magnetic characteristic. In this paper, a new and attractive CGSM, proposed originally by Kjær et al. [11], is for the first time implemented and analyzed. This particular low-cost method needs no a priori knowledge of the motor parameters, except the pole configuration, and it is, therefore, applicable to most SRM topologies.

\section{THEORY}

The SRM is usually controlled by either closed-loop current control or open-loop PWM voltage control.

There are three types of current control.

1) Hysteresis current control-The current is controlled between two current levels equal to $i_{\text {ref }} \pm \frac{\Delta i}{2}$ where $i_{\text {ref }}=$ reference current and $\Delta i=$ hysteresis band. The switching frequency is uncontrolled.

2) Delta modulation-The current is regulated around $i_{\text {ref }}$ with maximum switching frequency limited, also called bang-bang current control.

3) Current regulation with PWM-The current is regulated close to $i_{\text {ref }}$ using PWM.

In voltage control, a fixed switching frequency is used to modulate the chopping transistor. The PWM duty cycle is constant during one electrical cycle, but it can be varied to

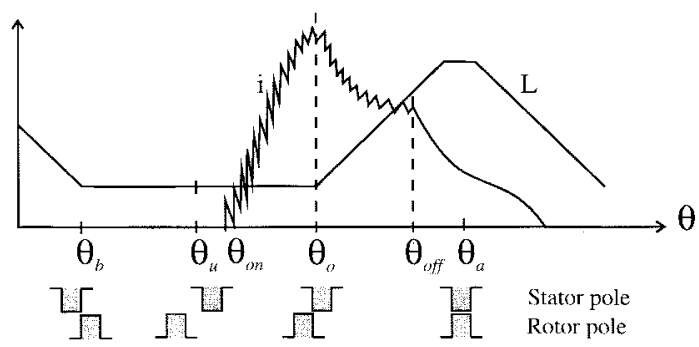

Fig. 3. Typical current waveform in PWM voltage control.

control the average phase voltage:

$$
V_{\mathrm{ph}}=D \cdot V_{\mathrm{dc}}
$$

where $V_{\mathrm{dc}}=$ dc-link voltage and $D=$ PWM duty cycle which is defined as the fraction of time that the switch is on with respect to the period of the switching frequency.

The simplest way is to leave $Q 2, Q 4$, and $Q 6$ on from $\theta_{\text {on }}$ to $\theta_{\text {off }}$ and chop $Q 1, Q 3$, and $Q 5$ at fixed frequency with its corresponding duty cycle (Figs. 2 and 3 ).

The main advantage of current control over voltage control is that the phase current can be controlled precisely, which means that reduction of torque ripple or noise is possible, however, it requires a current sensor for each phase. In contrast, voltage control typically requires only one current sensor in the dc link for overcurrent protection.

From the aforementioned, voltage control is attractive for low-power/low-cost SRM drives, due to the reduced number of current sensors and signal processing required. The theory behind CGSM is based on voltage control, and it is explained as follows.

The phase voltage can be expressed by

$$
v=R \cdot i+\omega \cdot L \cdot \frac{d i}{d \theta}+\omega \cdot i \cdot \frac{d L}{d \theta}
$$

where $L=$ phase inductance, $R=$ phase resistance, $i=$ phase current, $\omega=\frac{d \theta}{d t}=$ speed, and $\theta=$ rotor position.

Now, let $\theta_{o}$ be defined as the rotor position at which a rotor pole and a stator pole begin to overlap (i.e., where the phase inductance begins to increase), and consider two situations, one just before reaching $\theta_{o}$, referred to as " $O-$," and other just after passing $\theta_{o}$, referred to as " $O+$." The voltage equations for these two situations, neglecting the voltage drop in the phase 
resistance, become

$$
\begin{aligned}
& v_{o-}=\omega \cdot L_{o-} \cdot \frac{d i_{o-}}{d \theta}+\omega \cdot i_{o-} \cdot \frac{d L_{o-}}{d \theta} \\
& v_{o+}=\omega \cdot L_{o+} \cdot \frac{d i_{o+}}{d \theta}+\omega \cdot i_{o+} \cdot \frac{d L_{o+}}{d \theta} .
\end{aligned}
$$

The inductance at rotor position $\theta_{0}$ is ideally equal to the inductance at the unaligned rotor position $L_{u}$ (see Fig. 3):

$$
L_{o-} \approx L_{u}
$$

which yields

$$
\frac{d L_{o}}{d \theta}=0
$$

Therefore, the voltage equations for the two rotor positions can be rewritten as

$$
\begin{aligned}
& v_{o-}=\omega \cdot L_{u} \cdot \frac{d i_{o-}}{d \theta} \\
& v_{o+}=\omega \cdot L_{u} \cdot \frac{d i_{o+}}{d \theta}+\omega \cdot i_{o+} \cdot \frac{d L_{o+}}{d \theta} .
\end{aligned}
$$

\section{A. CGSM}

As the phase is turned on before $\theta_{o}$, the voltage is maintained constant in a stroke ${ }^{1}$ :

$$
v_{o-}=v_{o+}
$$

By manipulation of (7)-(9), we obtain

$$
\left(\frac{d i_{o-}}{d \theta}-\frac{d i_{o+}}{d \theta}\right)=\frac{i_{o+} \cdot \frac{d L_{o+}}{d \theta}}{L_{u}}
$$

As the right-hand side of (10) is positive, the following inequality is always true:

$$
\frac{d i_{o-}}{d \theta}>\frac{d i_{o+}}{d \theta}
$$

\section{The slope of the phase current is always larger for $\theta<\theta_{o}$ than for $\theta>\theta_{\circ}$.}

This is the core principle of the CGSM. Fig. 3 shows a typical current waveform for PWM voltage control. It is clear that, when the phase inductance starts to increase at $\theta_{O}, \frac{d i}{d \theta}$ must decrease, or even become zero.

1) CGSM for Switched Reluctance Generator: Let us define $\theta_{b}$ as the rotor position at which the rotor and stator poles seize to overlap. For generating, the phase is usually turned on before the aligned position $\theta_{a}$ and turned off after $\theta_{a}$, but before $\theta_{b}$ (Fig. 4). Assuming that the phase voltage is maintained constant while the current freewheels through the diodes, i.e., $V_{\mathrm{ph}}=-V_{\mathrm{dc}}$, we obtain

$$
\left(\frac{d i_{b+}}{d \theta}-\frac{d i_{b-}}{d \theta}\right)=\frac{i_{b-} \cdot \frac{d L_{b-}}{d \theta}}{L_{u}} .
$$

\footnotetext{
${ }^{1}$ One energy conversion in a single phase.
}

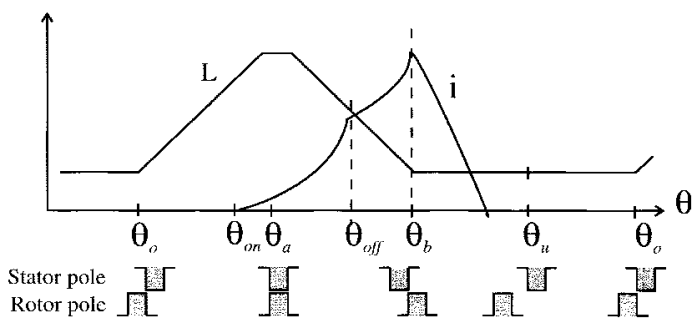

Fig. 4. Typical generated phase current.

As the right-hand side of (12) is always negative, the following inequality is always true:

$$
\frac{d i_{b-}}{d \theta}>\frac{d i_{b+}}{d \theta} \text {. }
$$

The slope of the generated phase current is always

$$
\text { larger for } \theta<\theta_{b} \text { than for } \theta>\theta_{b} \text {. }
$$

Fig. 4 shows a typical generated current waveform. It is clear that, when the phase inductance reaches its minimum value $L_{u}$ at $\theta_{b}, d i / d \theta$ must decrease.

From the aforementioned, we can say that an accurate indication of the rotor position can be detected for both motoring $\left(\theta_{o}\right)$ and generating $\left(\theta_{b}\right)$, simply by detection of the change in $d i / d t$ (assuming constant speed).

The CGSM senses $\theta_{o}$, which is given by the motor geometry. One rotor position is estimated per stroke, where the stroke angle in mechanical degrees is defined as

$$
\Delta \theta=\frac{360^{\circ}}{m \cdot N_{r}}
$$

where $N_{r}$ and $m$ are the number of rotor poles and the number of phases, respectively.

2) Advantages of CGSM: The most important advantages of the method are the following.

- No a priori knowledge of inductance profile is required.

- It is applicable to any regular SRM. ${ }^{2}$

- No prestored data of magnetization curves are needed.

- It is applicable in four-quadrant operation of the drive.

- It does not compromise the performance of the motor.

- It allows closed-loop speed control by changing the duty cycle, commutation angles, or both.

- The commutation angles can be set freely with the condition of $\theta_{\text {on }}<\theta_{o}$ (for motoring).

- Implementation is simple, with a minimum of extra components.

- Either the lower transistor bus current waveform $\left(i_{\text {bus }}\right)$ or the currents sensed in each phase are used as feedback. $i_{\text {bus }}$ allows operation with only one current sensor.

- No extra computation, control requirements, or compensation factors are needed.

- It allows excitation overlap.

- It is suitable for medium and high speed, given that the peak in the current waveform becomes more prominent with increased speed.

\footnotetext{
2 "A regular switched reluctance motor is one in which the rotor and stator poles are symmetrical about their centrelines and equally spaced around the rotor and stator respectively." [13]
} 


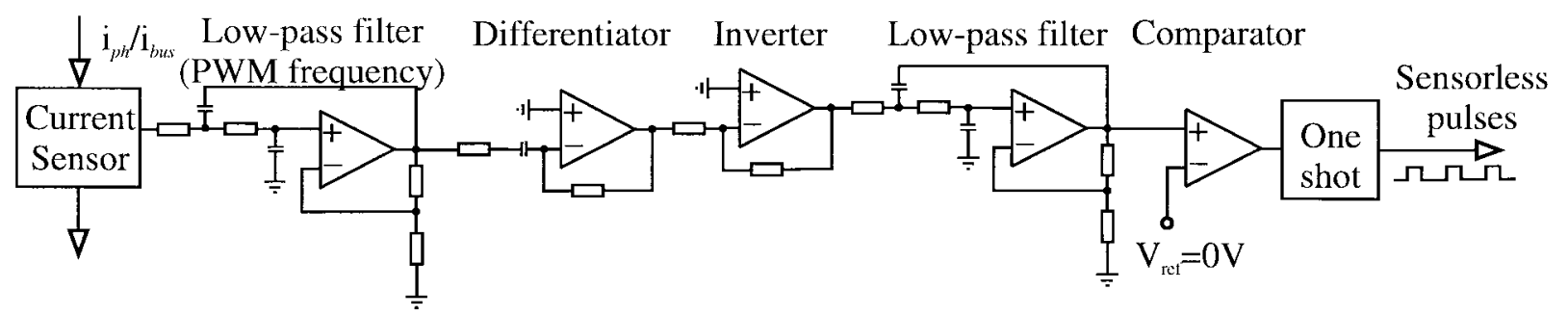

Fig. 5. Detection stage.

3) Disadvantages of CGSM: On the other hand, the disadvantages are as follows.

- It is not applicable at standstill.

- It needs a startup procedure.

- It is not suitable for low speed.

- It does not allow large load torque transients.

- Current regulation is not allowed for reduction of torque ripple or noise.

- It does not have very good efficiency at low speed and low torque.

\section{IMPLEMENTATION}

The CGSM has been implemented and analyzed for motoring. It is comparable to the back-EMF zero-crossing method of position estimation for brushless dc motors [12]. In a threephase brushless dc machine, the zero crossing of the back EMF indicates two positions per phase per cycle, while the method presented here, according to (11), indicates one position per phase per cycle and, from these pulses, commutation angles can be obtained. Both motors need a startup procedure (feedforward) when operated without a position sensor.

The block diagram for the fully analog electronic detection circuit is shown in Fig. 5. It is comprised of a current sensor, two low-pass filters, a differentiator, and a zero-crossing detector. The low-pass filters are used to eliminate the switching frequency and possible noise. For each low-pass filter, a second-order Butterworth filter was used, where the cutoff frequency is determined by the PWM switching frequency. In this case, a cutoff frequency of $8 \mathrm{kHz}$ was used for a switching frequency of $16 \mathrm{kHz}$. The differentiator is used to obtain $d i / d t$, and the zero-crossing detector gives a pulse when $d i / d t$ is zero. For simplicity, $d i / d t=0$ is detected, which puts constraints on the current waveform that should have at least one peak. However, a detection stage that detects the change in $d i / d t$, rather than $d i / d t=0$, could be implemented. If the drive is going to be operated in single-pulse mode (i.e., $D=1$ ) the low-pass filters are not necessary, and the number of components in the detection stage is reduced significantly. It should be noted that the electronic circuitry required for the CGSM is minimal (operational amplifiers, resistors, and capacitors), with obvious scope for implementation as a singlechip solution.

Fig. 6 shows the block diagram of the sensorless SRM drive. The sensorless position estimation pulses can be generated either by each phase current $\left(i_{\mathrm{ph} 1}, i_{\mathrm{ph} 2}, i_{\mathrm{ph} 3}\right)$ or the current in the lower transistor bus ( $i_{\text {bus }}$, see Fig. 2 ), which contains the same information as the phase currents required for motoring

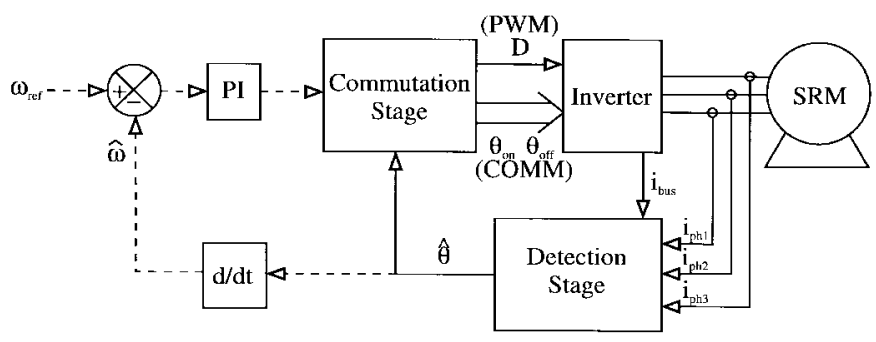

Fig. 6. Block diagram of sensorless SRM drive.

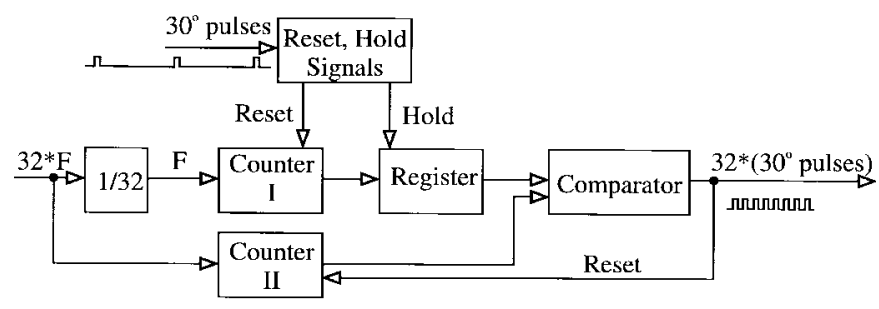

Fig. 7. Block diagram of phase-locked loop (PLL) position interpolation.

operation. A single pulse train containing all the required information is obtained from either a single detection circuit sensing $i_{\text {bus }}$ or the combination of (OR-gate) sensorless pulses from each phase. Another option that uses only one detection circuit is to multiplex all phase currents.

The commutation stage is implemented with a fieldprogrammable gate array (FPGA) (Xilinx XC3195A) for flexibility in the development stage, but it could be realized with simple, low-cost digital, or even analog, components.

The sensorless pulses are used to generate a position counter as follows. The train of sensorless pulses spaced $30^{\circ}$ [according to (14)], obtained from the detection circuit, is used to generate a pulse train with 32 pulses per $30^{\circ}$. In other words, the frequency of the sensorless pulses is multiplied by 32 (using a PLL). Fig. 7 shows the block diagram of the implemented logic circuitry. There are two counters, counter I running at frequency $F$ and counter II running at frequency $32 * F$. Upon the arrival of a sensorless pulse, the value of counter I is first held in a register, and then, the counter is reset. The value of counter II builds up to the value in the register. When its value equals the register's value, the comparator generates a pulse and resets counter II. So, a resolution of 384 pulses per revolution is obtained, which is enough to generate commutation pulses with adequate resolution.

A microcontroller (Motorola MC68332) is used to close the speed loop and to analyze this sensorless scheme (less 


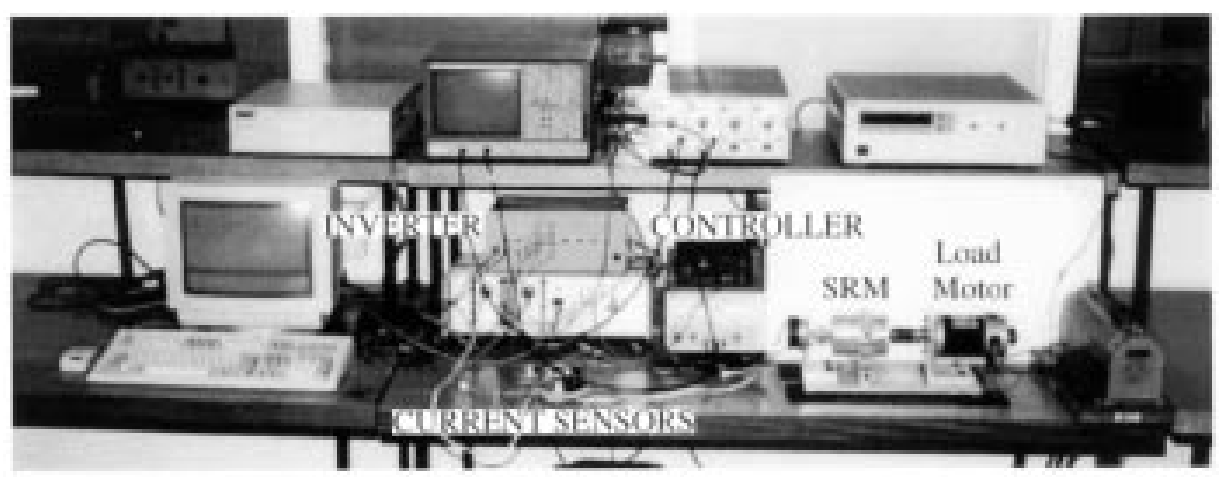

Fig. 8. Hardware overview.

powerful microcontrollers could be used). A classic inverter topology with two transistors and two diodes per phase is used with the variation of splitting the lower rail into two buses, the lower diode bus and the lower transistor bus (Fig. 2), so that the current in the commutating transistors can be observed by $i_{\text {bus }}$. The experiments have been carried out with both one single detection circuit and one detection circuit per phase. It was found that using $i_{\text {bus }}$ does not compromise the drive's performance in any way.

A proportional integral (PI) closed-loop speed controller, which varies the PWM duty cycle for load compensation (as indicated in Fig. 6), has been implemented. The firing angles are programmable and can be varied easily to control the motor torque, but they remained fixed in the dynamic tests conducted here. The only operating constraint is to assure $\theta_{\text {on }}<\theta_{o}$, which is not an onerous restriction at any operating speed or torque.

\section{EXPERIMENTAL RESULTS}

A fractional horsepower 6/4 three-phase SRM was used to investigate the performance and limitations of the new method. The test motor and the load machine were coupled with flexible rubber couplings. The load machine was a PM motor connected in series with a resistance and a current-controlled power supply. The complete setup is shown in Fig. 8.

The experiments include detection of sensorless pulses, accuracy in rotor position estimation, speed transients, torque transients, and the assessment of torque-speed range where the motor can be operated sensorless. The angles are represented in mechanical degrees.

Fig. 9(a) shows one phase current $\left(i_{\mathrm{ph} 1}\right)$, lower transistor bus current $\left(i_{\text {bus }}\right)$, the current gradient position estimation (CGPE) pulses obtained from $i_{\text {bus }}$, and the decoded pulses (DP) for phase 1 measured at $1763 \mathrm{r} / \mathrm{min}$ with $\theta_{\text {on }}=50^{\circ}$, $\theta_{\text {off }}=80^{\circ}$. Clearly, the correct rotor position is detected. Fig. 9(b) illustrates the case of excitation overlap, showing $i_{\text {ph1 }}, i_{\text {bus }}$, CGPE, and DP for phase 1 measured at 1820 $\mathrm{r} / \mathrm{min}$, with $\theta_{\text {on }}=50^{\circ}, \theta_{\text {off }}=84^{\circ}$. Note that this time, two sensorless pulses appear per stroke; the first one is erroneous (when the previous phase is turned off), and the second one gives $\theta_{o}$. A simple logic circuit neglects the first pulse when there is excitation overlap, so DP becomes the decoded signal for phase 1. Fig. 10(a) depicts the estimated position $\hat{\theta}$ and the position given by the 1024-line encoder $\theta$ in steady state

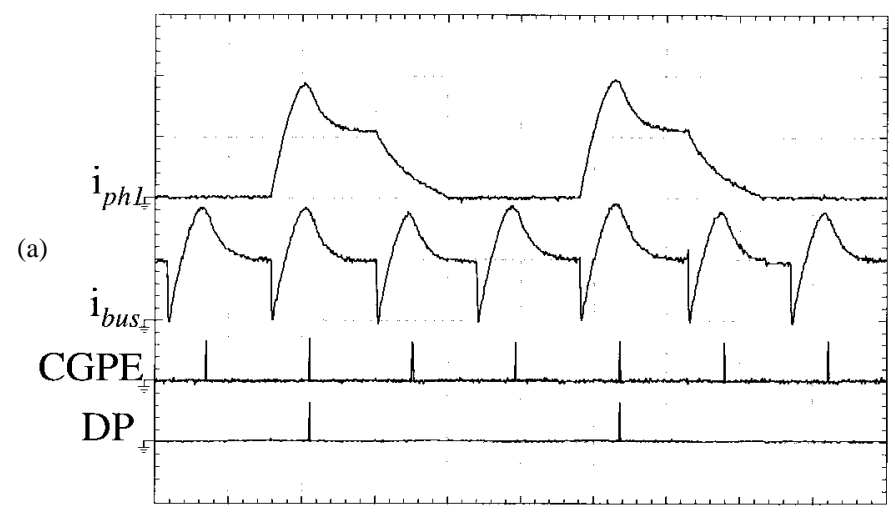

$2 \mathrm{~ms} / \mathrm{div} ., 1 \mathrm{~A} / \mathrm{div}$. and 10V/div.

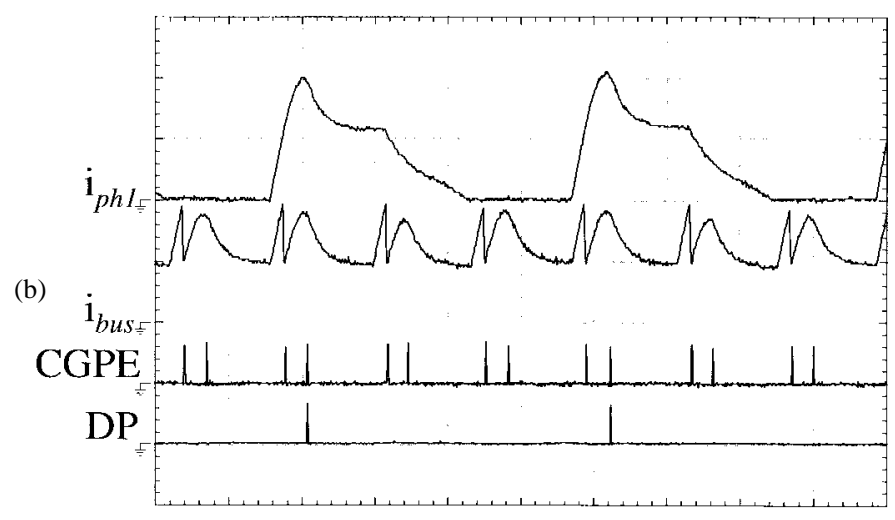

$2 \mathrm{~ms} / \mathrm{div} ., 1 \mathrm{~A} / \mathrm{div}$. and $10 \mathrm{~V} / \mathrm{div}$.

Fig. 9. Single-pulse current waveforms. (a) $\theta_{\text {on }}=50^{\circ}, \theta_{\text {off }}=80^{\circ}$ (no excitation overlap). (b) $\theta_{\text {on }}=50^{\circ}, \theta_{\text {off }}=84^{\circ}$ (excitation overlap).

measured at $2304 \mathrm{r} / \mathrm{min}$, with $\theta_{\text {on }}=45^{\circ}, \theta_{\text {off }}=80^{\circ}$. Clearly, the position signals show good agreement. Fig. 10(b) shows $\hat{\theta}_{o m}, \theta_{\mathrm{on}}, \Delta \theta_{g}$, and $\Delta \theta_{m}$, where $\Delta \theta_{g}=\hat{\theta}_{o m}-\theta_{o g}$ and $\Delta \theta_{m}=\hat{\theta}_{o m}-\theta_{o m} . \theta_{o g}=52.2^{\circ}$ is defined as the position where the mechanical overlap occurs, i.e., where the rotor and stator poles start to overlap and it is calculated from the stator and rotor pole arcs. $\theta_{o m}$ is defined as the position where the magnetic overlap occurs, obtained from experimental results. It can be observed that, for speeds above $800 \mathrm{r} / \mathrm{min}, \Delta \theta_{g}$ is quite constant and around $3^{\circ}$. This difference shows us that the magnetic overlap differs from the mechanical overlap by $3^{\circ}$, which gives

$$
\theta_{o m}=\theta_{o g}+3^{\circ}=55.2^{\circ}
$$


(a)

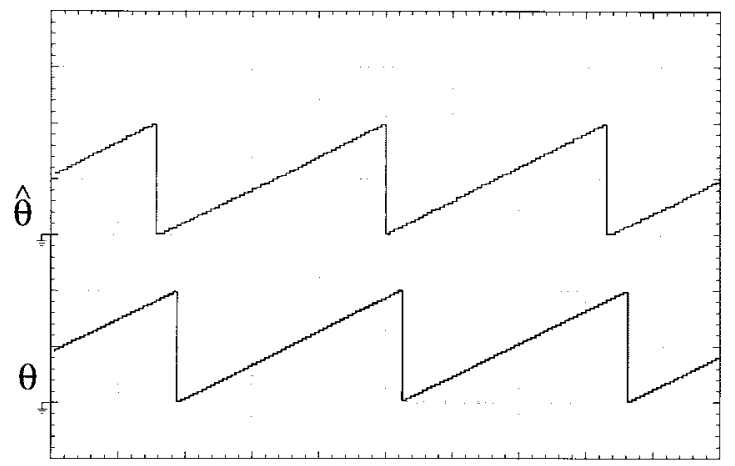

$2 \mathrm{~ms} / \mathrm{div} ., 5 \mathrm{~V} / \mathrm{div}$.

(b)

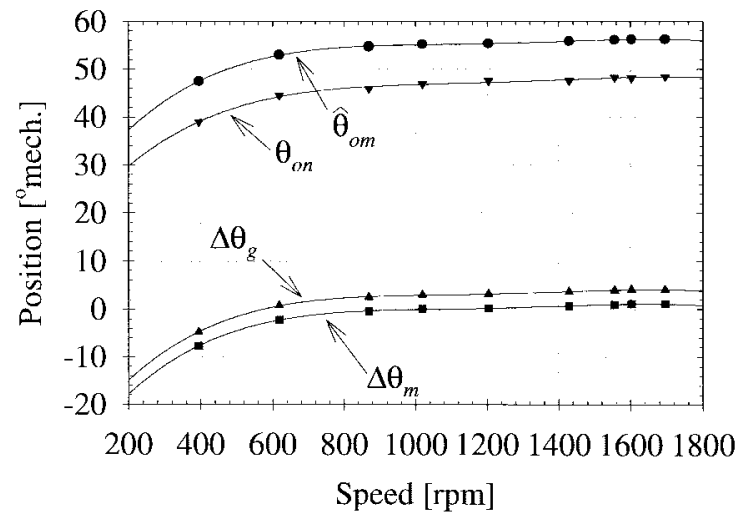

Fig. 10. (a) CGSM position estimation at $2304 \mathrm{r} / \mathrm{min}$ in single pulse with $\theta_{\text {on }}=45^{\circ}, \theta_{\text {off }}=80^{\circ}$. (b) Measured accuracy of CGSM in steady state.

where $\theta_{o m}$ represents the real position. Hence, the firing angles are shifted $3^{\circ}$ (only $\theta_{\text {on }}$ is shown). Also, we observed that above $800 \mathrm{r} / \mathrm{min} \Delta \theta_{m}$ is close to zero, which means that the position estimation hardly differs from the real position. In contrast, at low speed, there is a deviation of position estimation. This deviation in position estimation is caused by the accuracy in detecting $d i / d t=0$. The most important factors influencing this detection are that the gain of the differentiator is sensitive to frequency, and the comparator amplifier may be offset, i.e., $V_{\text {ref }} \neq 0$. On the other hand, at high speed, the pulses may be delayed by the phase lag of the low-pass filters. However, position deviations can be corrected in the commutation angle controller as a function of speed.

\section{STARTUP}

It is a requirement of the CGSM that the phases conduct nonzero current, but, also, that the waveform resembles that of Fig. 3. To bring the motor into running mode, the following two options can be used.

1) Feedforward-The motor is controlled feedforward in open-loop as a stepper motor [12]. A train of pulses with initial frequency is applied to the motor windings in a sequence according to the desired direction. The frequency is increased linearly, and it is assumed that the rotor follows it.

2) Active probing - This method makes use of small current pulses in all phase windings in order to identify the inductance and. hence, rotor position at standstill. With this information, the correct phase can be energized according to the desired direction of rotation.

Once the first phase in energized, small probing pulses are injected in the phase next to be energized. The rotor position is extracted by the probing pulses, and it is used for phase commutation [1], [4]. It should be noted that a current sensor for each phase may be needed.

In both cases, the motor must be accelerated from standstill to the speed where the waveform conditions are met and, therefore, sensorless pulses can be detected. Feedforward was chosen due to its simplicity and reduction of number of current sensors.

\section{A. Feedforward Method}

The goal is for the motor to generate enough torque to accelerate up to the speed at which the CGPE pulses can be detected. The takeover speed is defined as the speed at which the motor goes from being operated in feedforward to true sensorless operation (feedback). This method permits a reliable and smooth, but neither efficient nor optimal, startup of the motor, even under load. A train of pulses is applied to each phase in a sequence according to the direction of rotation. The dwell angle ${ }^{3}$ is fixed and equal to $30^{\circ}$. Each phase pulse train is phase shifted $30^{\circ}\left(120^{\circ}\right.$ elec.). To accelerate the motor, the frequency is increased linearly to a value determined by a predefined takeover speed, while a $100 \%$ PWM duty cycle is applied and is decreased linearly to a final value according to the load torque at the takeover point. The startup procedure for a takeover speed of 500,750, and $1000 \mathrm{r} / \mathrm{min}$ was simulated, and the PWM duty cycle was decreased to $33 \%, 50 \%$, and $67 \%$, respectively, in order to assure the current waveform where CGPE pulses can be detected. Fig. 11(a) shows the results. For the case of takeover at $1000 \mathrm{r} / \mathrm{min}$, three traces are shown which correspond to different accelerations. The ramp time can be adjusted depending on the load torque. It is important to mention that the condition required for the CGSM may not be met for speeds below $200 \mathrm{r} / \mathrm{min}$, for the particular drive analyzed here.

Fig. 11(b) depicts $\theta_{\text {on }}$ and $\theta_{\text {off }}$, corresponding to a takeover speed of $1000 \mathrm{r} / \mathrm{min}$ with a ramp time of $2 \mathrm{~s}$. The ripple shows how the commutation angles move in order to match the load torque during the startup sequence (as a stepper). It is clear that $\theta_{\mathrm{on}}$ occurs before $\theta_{a}$, and $\theta_{\text {off }}$ occurs after $\theta_{a}$. At the takeover speed, $\theta_{\mathrm{on}}$ is around $43^{\circ}$ and $\theta_{\text {off }}$ is around $73^{\circ}$; at this time $\theta_{O}$ can be estimated. Fig. 11(c) depicts the instantaneous torque during startup. It shows that, at the beginning, there are significant torque oscillations, but these are limited at the takeover point.

Fig. 12(a) depicts the experimental result during startup. The signal is measured with a 1024-line encoder. Initially, $76-\mathrm{Hz}(380 \mathrm{r} / \mathrm{min})$ excitation frequency is applied for a short period, and then, the frequency is increased linearly up to 230 $\mathrm{Hz}$, at which the takeover speed of $1150 \mathrm{r} / \mathrm{min}$ is reached. The duty cycle is maintained at $100 \%$. Once the takeover speed has been reached, the CGPE pulses can be used to commutate the

\footnotetext{
${ }^{3}$ Dwell angle is defined as the commutation period over an electrical cycle, i.e., $\theta_{\text {off }}-\theta_{\text {on }}$.
} 
(a)

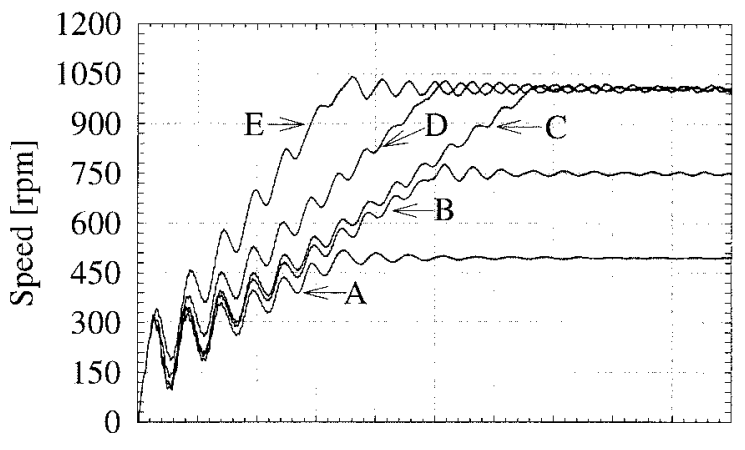

$0.3 \mathrm{~s} / \mathrm{div}$.

(b)

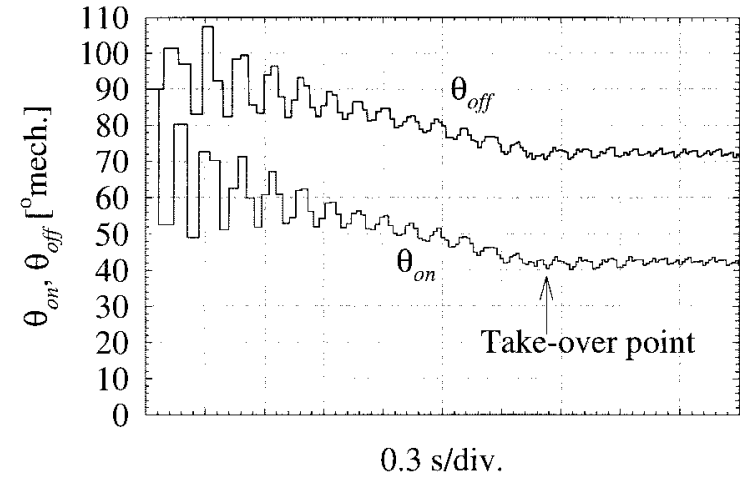

(c)

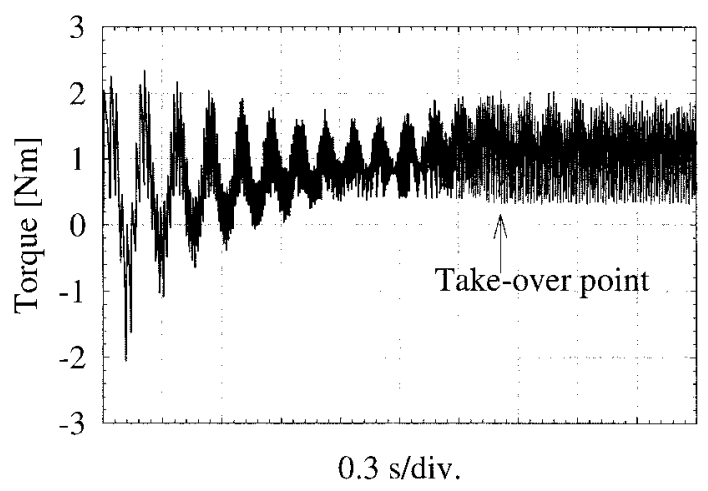

Fig. 11. CGSM feedforward startup (simulated). (a) Speed for different accelerations- $A: 500 \mathrm{r} / \mathrm{min}, 1 \mathrm{~s} ; B: 750 \mathrm{r} / \mathrm{min}, 1.5 \mathrm{~s} ; C: 1000 \mathrm{r} / \mathrm{min}, 2 \mathrm{~s}$; $D: 1000 \mathrm{r} / \mathrm{min}, 1.5 \mathrm{~s} ; E: 1000 \mathrm{r} / \mathrm{min}, 1 \mathrm{~s}$. (b) Firing angles. (c) Instantaneous torque.

phases in closed loop. Fig. 12(b) shows $i_{\mathrm{ph} 1}, i_{\mathrm{bus}}$, and CGPE measured during transition from open-loop to sensorless mode at takeover speed of $1339 \mathrm{r} / \mathrm{min}$ with $\theta_{\text {on }}=50^{\circ}, \theta_{\text {off }}=80^{\circ}$.

Fig. 13(a) shows $i_{\text {ph1 }}$ and $i_{\text {bus }}$ measured during the startup sequence. It can be seen that, at the beginning, the current is limited through chopping by a preset maximum current value and, as the speed goes up, the peak current is reduced. Once the takeover speed has been reached, the CGPE pulses can be used for commutation.

Now, examples of sensorless closed-loop speed control are discussed. A PI controller acts on the PWM duty cycle for dynamic compensation. The firing angles remain fixed at $\theta_{\text {on }}=48^{\circ}, \theta_{\text {off }}=78^{\circ}$. Fig. 13(b) shows $i_{\mathrm{ph} 1}$ and $i_{\text {bus }}$ measured during transition from open-loop to sensorless mode with closed-loop speed control with a reference speed of 1092 $\mathrm{r} / \mathrm{min}$. An example of the drive's response to steps in speed reference is shown in Fig. 14(a) for sensorless mode and Fig. 14(b) with a 1024-line encoder. Clearly, the performance (a)

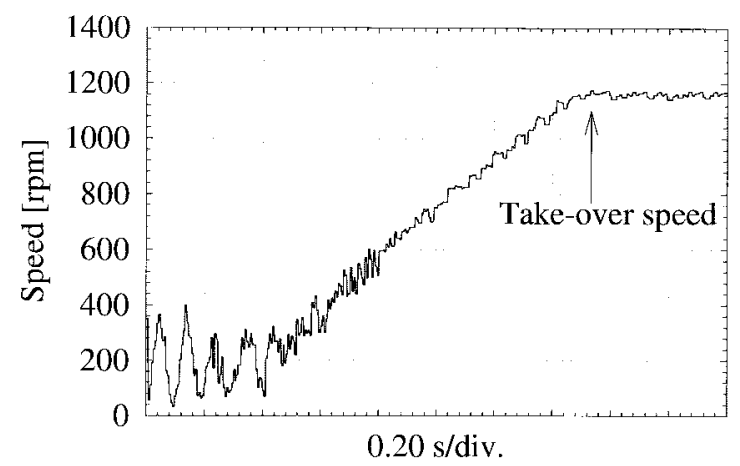

(b)

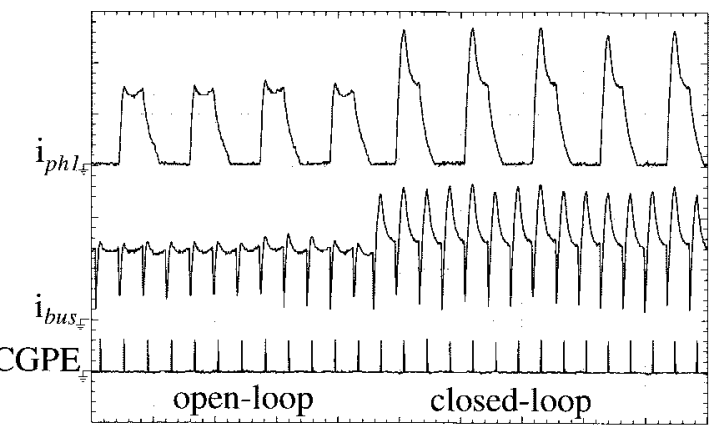

$10 \mathrm{~ms} / \mathrm{div} ., 1 \mathrm{~A} / \mathrm{div}$, and $10 \mathrm{~V} / \mathrm{div}$.

Fig. 12. (a) CGSM feedforward startup (the signal is measured with a 1024-line encoder). (b) Zoom of takeover at $1339 \mathrm{r} / \mathrm{min}$ with $\theta_{\text {on }}=50^{\circ}, \theta_{\text {off }}=80^{\circ}$.

(a)

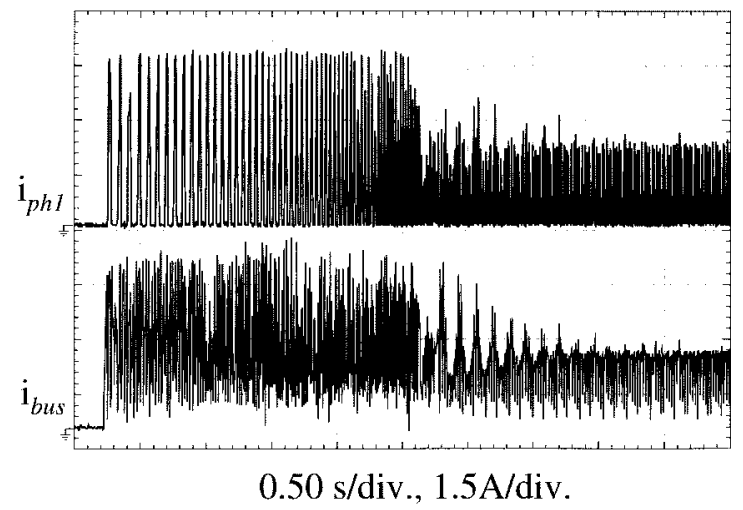

(b)

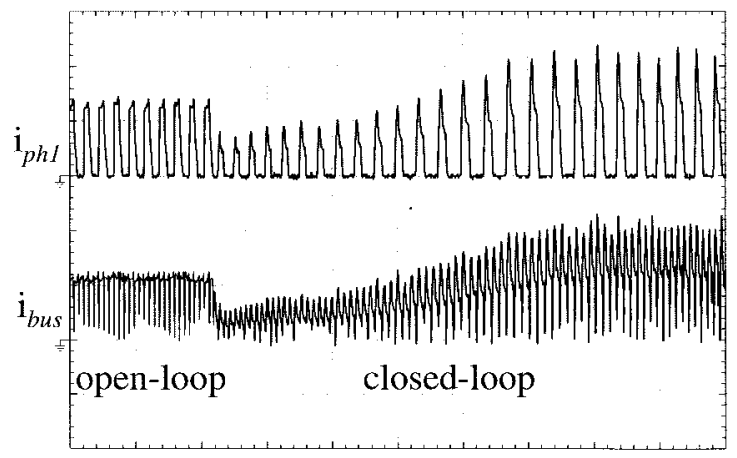

$50 \mathrm{~ms} / \mathrm{div} ., 1 \mathrm{~A} / \mathrm{div}$.

Fig. 13. (a) Current waveform measured during feedforward startup. (b) Takeover measured at speed $=1339 \mathrm{r} / \mathrm{min}$ with $\theta_{\text {on }}=50^{\circ}, \theta_{\text {off }}=80^{\circ}$, swapping to closed-loop speed control with a reference speed of $1092 \mathrm{r} / \mathrm{min}$. 
(a)

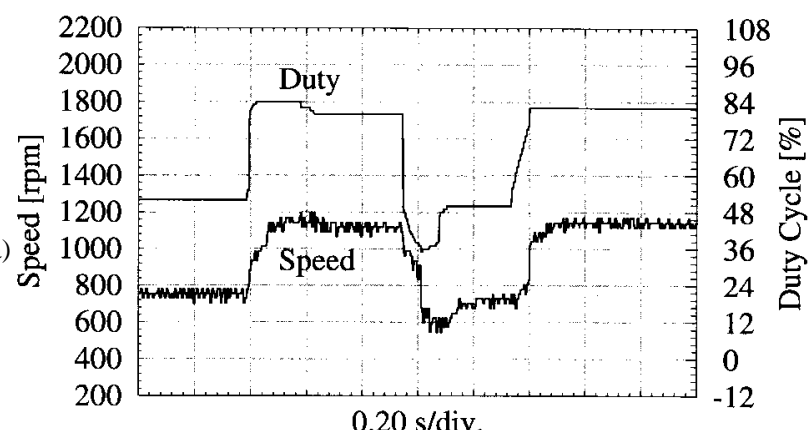

(b)

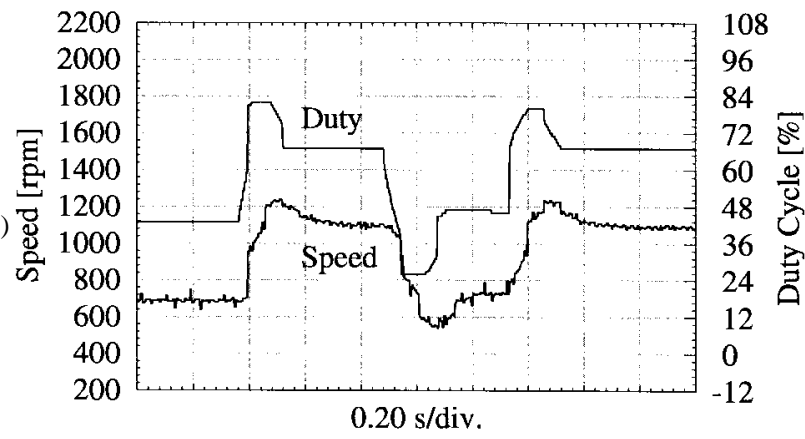

Fig. 14. Zoom of speed transients. (a) Sensorless CGSM $\theta_{\text {on }}=48^{\circ}$, $\theta_{\text {off }}=78^{\circ}$. (b) With sensor $\theta_{\text {on }}=42^{\circ}, \theta_{\text {off }}=72^{\circ}$.

(a)

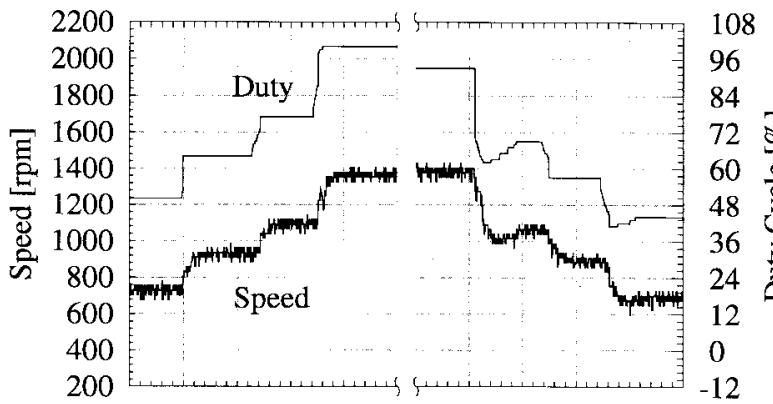

(b)

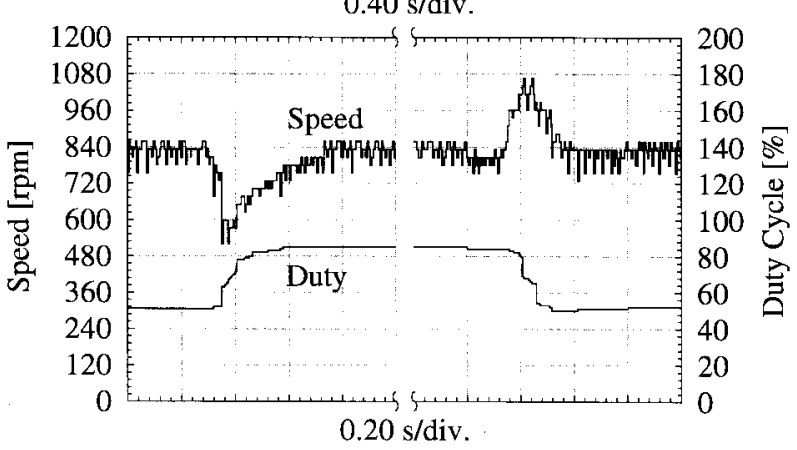

Fig. 15. (a) Measured sensorless speed transients. (b) Transient response to a load torque step of $0.42 \mathrm{~N} \cdot \mathrm{m}$ (0.6 p.u.).

is comparable both with and without encoder feedback.

Fig. 15(a) depicts a series of speed transients and Fig. 15(b) shows the sensorless drive's response to a step of $0.42 \mathrm{~N} \cdot \mathrm{m}$ in load torque ( 0.6 p.u.), with $\theta_{\text {on }}=50^{\circ}$ and $\theta_{\text {off }}=79^{\circ}$. This demonstrates that closed-loop CGSM could be acceptable in many low-cost variable-speed applications.

Finally, Fig. 16 depicts the torque-speed characteristic of the three-phase 6/4 SRM used and also shows in which region the CGSM can be applied. It is clear that in the range from 0

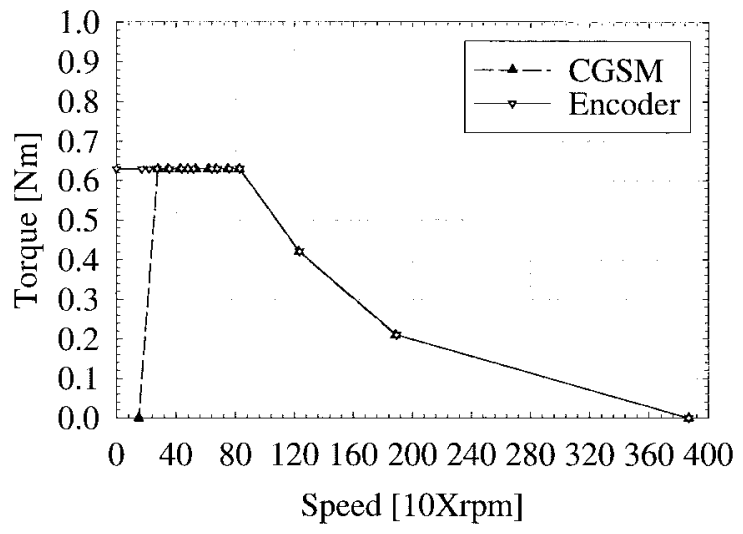

Fig. 16. Measured torque-speed characteristic with and without position sensor.

to approximately $200 \mathrm{r} / \mathrm{min}$, estimation of rotor position is not possible. However, at higher speeds, CGSM does not put any limitation on the torque-speed motor characteristic.

\section{CONCLUSION}

This paper has experimentally demonstrated for the first time the functionality of a new rotor position estimation method for SR motors operated in PWM voltage control, detecting one rotor position per phase per electrical cycle, with no a priori knowledge of motor parameters. The method is comparable in performance and complexity to the back-EMF method for brushless dc motors.

Experimental results confirm the theory and prove the concept of the new CGSM. The position estimation can be detected with either one detection circuit per phase or, preferably, with just one for the lower transistor bus current, even with excitation overlap. It should be noted that the only cost added by this scheme is the detection circuit, which uses a few low-cost components.

The firing angles can be varied freely with the condition of $\theta_{\mathrm{on}}<\theta_{o}$, which is otherwise necessary to produce adequate torque at high efficiency [13]. Feedforward (open loop) is used to accelerate the motor smoothly from zero speed up to a maximum frequency which is determined by the desired takeover speed. A closed-loop speed PI controller was implemented in sensorless mode, and a series of speed and torque transients demonstrated the feasibility of closing the speed loop by controlling the PWM duty cycle.

In summary, we may conclude that the CGPE allows estimation of one rotor position per stroke with no a priori knowledge of the motor parameters, except the pole configuration. It is, therefore, applicable to most SRM topologies in a wide power and speed range and for most inverter topologies. The method allows the control of the SRM drive in two quadrants by controlling the commutation angles and PWM duty cycle, but could be expanded to four-quadrant operation or continuous generator operation. The scheme is mainly suited for medium- and high-speed applications, and this simple and low-cost implementation may allow the SRM technology into a range of air-moving and pump applications and even domestic appliances. 


\section{ACKNOWLEDGMENT}

The authors would like to thank C. Cossar, I. Young, J. Kelly, and P. Miller for help in the test equipment.

\section{REFERENCES}

[1] P. P. Acarnley, R. J. Hill, and C. W. Hooper, "Detection of rotor position in stepping and switched reluctance motors by monitoring of current waveforms," IEEE Trans. Ind. Electron., vol. 32, pp. 215-222, June 1985.

[2] J. P. Lyons, S. R. MacMinn, and M. A. Preston, "Flux/current methods for SRM rotor position estimation," in Proc. IEEE-IAS Annu. Meeting, 1991, pp. 482-487.

[3] G. Hedlund and H. Lundberg, "Motor energizing circuit," U.S. Patent 4868 478, Sept. 19, 1989.

[4] S. R. MacMinn, W. J. Rzesos, P. M. Szczesny, and T. M. Jahns, "Application of sensor integration techniques to switched reluctance motor drives," in Proc. IEEE-IAS Annu. Meeting, 1988, pp. 584-588.

[5] M. Ehsani, I. Husain, and A. B. Kulkarni, "Elimination of discrete position sensor and current sensor in switched reluctance motor drives," IEEE Trans. Ind. Applicat., vol. 28, pp. 128-135, Jan./Feb. 1992.

[6] M. Ehsani, I. Husain, S. Mahajan, and K. R. Ramani, "New modulation encoding techniques for indirect rotor position sensing in switched reluctance motors," IEEE Trans. Ind. Applicat., vol. 30, pp. 85-91, Jan./Feb. 1994

[7] I. Husain and M. Ehsani, "Rotor position sensing in switched reluctance motor drives by measuring mutually induced voltages," IEEE Trans. Ind. Applicat., vol. 30, pp. 665-672, May/June 1994.

[8] P. Laurent, M. Gabsi, and M. Multon, "Sensorless rotor position analysis using resonant method for switched reluctance motor," in Proc. IEEEIAS Annu. Meeting, 1993, pp. 687-694,
[9] J. T. Bass, M. Ehsani, and T. J. E. Miller, "Robust torque control of switched-reluctance motors without a shaft position sensor," IEEE Trans. Ind. Electron., vol. IE-33, pp. 212-216, Aug. 1986.

[10] A. H. Lumsdaine and J. H. Lang, "State observers for variable-reluctance motors," IEEE Trans. Ind. Applicat., vol. 37, pp. 133-142, Mar./Apr. 1990.

[11] P. C. Kjær, F. Blaabjerg, J. K. Pedersen, P. Nielsen, and L. Andersen, "A new indirect rotor position detection method for switched reluctance drives," in Proc. ICEM'94, Paris, France, 1994, vol. 2, pp. 555-560.

[12] K. Iizuka, H. Uzuhashi, M. Kano, T. Endo, and K. Mohri, "Microcomputer control for sensorless brushless motor," IEEE Trans. Ind. Applicat., vol. 21, pp. 595-601, May/June 1985.

[13] T. J. E. Miller, "Switched reluctance motors and their control," in Monographs in Electrical and Electronic Engineering. Oxford, U.K.: Clarendon, 1993.

Gabriel Gallegos-López (S’93), for a photograph and biography, see p. 451 of the May/June isssue of this Transactions

Philip C. Kjaer (S'92-M'93), for a photograph and biography, see p. 451 of the May/June isssue of this Transactions.

Timothy J. E. Miller (M'74-SM'82-F'96), for a photograph and biography, see p. 428 of the May/June isssue of this TransaCtions. 